\title{
Theory and Application of Gob-Side Entry Retaining in Thick Three-Soft Coal Seam
}

\author{
Junchao Shen $\mathbb{D}^{1,2}$ and Ying Zhang $\mathbb{D}^{3}$ \\ ${ }^{1}$ School of Energy Science and Engineering, Henan Polytechnic University, Jiaozuo, Henan 454000, China \\ ${ }^{2}$ Changzhi Vacational and Technical College, Changzhi, Shanxi 046000, China \\ ${ }^{3}$ ZhongYun International Engineering Co., Ltd., Zhengzhou, Henan 450007, China
}

Correspondence should be addressed to Ying Zhang; zhongyunzhangying@163.com

Received 27 April 2021; Accepted 5 June 2021; Published 2 July 2021

Academic Editor: Bin Gong

Copyright (c) 2021 Junchao Shen and Ying Zhang. This is an open access article distributed under the Creative Commons Attribution License, which permits unrestricted use, distribution, and reproduction in any medium, provided the original work is properly cited.

With the characteristic of less roadway excavation and high resource recovery, gob-side entry retaining (GER) technology is a safe and efficient green mining technology. Many experts and scholars have done extensive research on its principle and application. However, GERs are rarely used in thick soft coal seams. In this paper, based on the geological conditions of a coal mine in China, we propose a novelty approach of GER in thick three-soft coal seam (it means a single seam with a soft roof and a soft floor). The engineering scheme includes roadway expansion, large section roadway support, cutting roof to relieve pressure, and road-inside backfill body construction. The established mechanical and numerical calculation models effectively guide the engineering practice. Field observations showed that all the processes met the requirements of field production. The research results could provide theoretical guidance for the application of GER under similar geological conditions.

\section{Introduction}

China's coal production ranks first in the world, accounting for $51 \%$ of the world's total coal output in 2020 and accounting for more than $57 \%$ of the country's primary energy consumption. Coal will play an important role in China's energy structure for a long time [1-3].

Most coal mines in China are underground mines with about $12,000 \mathrm{~km}$ of underground roadway excavated each year. Section roadways account for more than $70 \%$ these roadways. In traditional longwall mines, $20-50 \mathrm{~m}$ wide coal pillars are allowed to remain between longwall panels to reduce the impact of mine-induced stress (Figure 1(a)). These wide pillars constitute a huge loss of coal resources. With the development of theoretical research on underground support for stopes, procedures for gob-side entry driving with narrow coal pillars have been developed (Figure 1(b)). Gob-side entry driving significantly improves coal recovery; however, the narrow coal pillars may be damaged by mining pressure resulting in air leakage into the goaf [4]. This can lead to spontaneous combustion or other mine disaster accidents $[5,6]$. With both wide coal pillars and gobside entry driving, there are many difficulties including increased roadway driving work and interference of the replacement between adjacent working faces. Therefore, it is urgent to adopt a method for driving roadways that is efficient, green, and safe.

Over the last few years, gob-side entry retaining (GER) has been developed and proven to be a reliable mining procedure. Gob-side entry retaining preserves the headentry as the tailentry for the next panel, and it can also reduce the amount of excavation and support work and improve the rate of coal extraction (see Figure 1(c)). Gob-side entry retaining uses gangue, masonry block, paste backfill material, high water content material, or other filling materials to construct roadside backfill bodies at the edge of the gob. This backfill body 


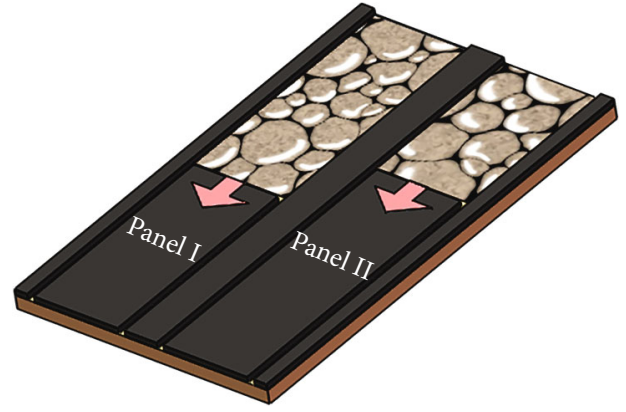

(a)

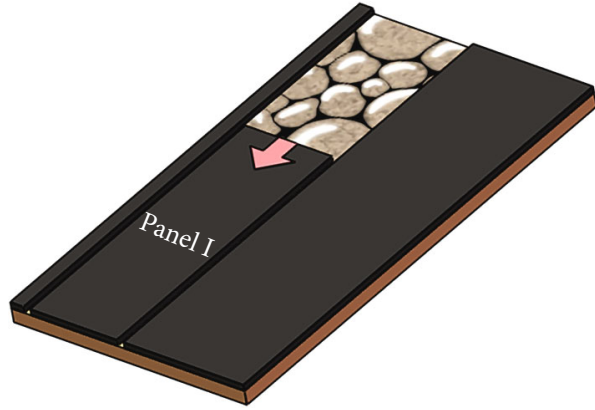

(b)

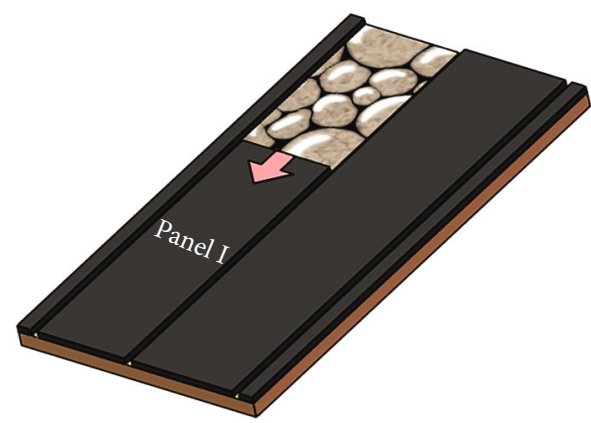

(c)

Figure 1: Sketches illustrating three different section roadway layouts. (a) Traditional longwall with wide coal pillar. (b) Gob-side entry driving (GED) with narrow coal pillar. (c) Gob-side entry retaining (GER) with noncoal pillar.

can isolate the gob from the retained entry, cut off the main roof above the gob, and prevent bed separation between the immediate roof and main roof [7].

As a safe and efficient green mining method, research organizations and many scholars in the main mining countries have carried out extensive research on GER. Scientists and engineers in Britain developed a mechanized device for constructing masonry gangue walls and succeeded in an experiment with a cemented masonry-filled gangue body. A high-water packing material was developed in 1979. Investigators in Germany developed low-water material mainly composed of gypsum, fly ash, cement, and gangue that they used to fill one side of a gob-side entry. The engineers in the former Soviet Union designed a variety of supports for gob-side entry. They also made a large number of observations by laboratory research and field test [8]. Since the 1990s, some mines in China have used supports with a formwork to cast concrete for roadside support. In 2002, Wei developed flexible formwork with water and slurry permeability and supporting mechanical equipment [9]. In 2009, he proposed the method of automatically formed GER for longwall working face, with the broken expand characteristics of the falling gangue to filling the roadside $[10,11]$.

At present, for simple geological conditions like thin or medium-thick coal seams with hard roofs and floors, GER procedures are relatively mature. However, for the application of GER in thick three-soft coal seam (TTCS), there are few theoretical research and strata control technology; many key technologies would still to be solved.

For this paper, TTCS in the Zhaojiazhai coal mine, Zhengzhou City, Henan Province, China, was chosen for research. The application of GER to TTCS was studied by theoretical analysis, numerical simulations, and field tests. The research results have theoretical and engineering reference value for promoting GER technology.

The Zhaojiazhai mine's designed production capacity is 3.0 Mt/a. The test site, 12209 working face, is in the east wing of No. 12 mining area. At present, the $2_{1}$ coal seam, with an average thickness of $6.5 \mathrm{~m}$ buried approximately $300 \mathrm{~m}$, is the main seam being mined, with fully mechanized longwall top-coal caving employed. The location of the mine and a sketch map of the 12209 working face are shown in Figure 2.

The immediate roof of 2 seam is sandy mudstone with an average thickness of $2.3 \mathrm{~m}$. The main roof is a finegrained sandstone with an average thickness of $20 \mathrm{~m}$. The immediate floor, averaging $8.86 \mathrm{~m}$ thick, is a sandy mudstone. Figure 3 is a stratigraphic column with a listing of the physical and mechanical properties of the rock surrounding the roadway.

The $2{ }_{1}$ coal seam, with its low strength and soft immediate roof and floor, is a typical three-soft coal seam $[12,13]$. The roof of the 12209 headentry is top coal with $2-3 \mathrm{~m}$ thickness. The main roof is a thick and hard fine-grained sandstone which has a large expanse suspended over the goaf [14]. If no remedial measures are employed, the GER may not succeed.

\section{Project Design and Implementation}

2.1. Project Design. The overall aim of this project was to construct GER in TTCS. The technical considerations leading up to the project's design are described below. 

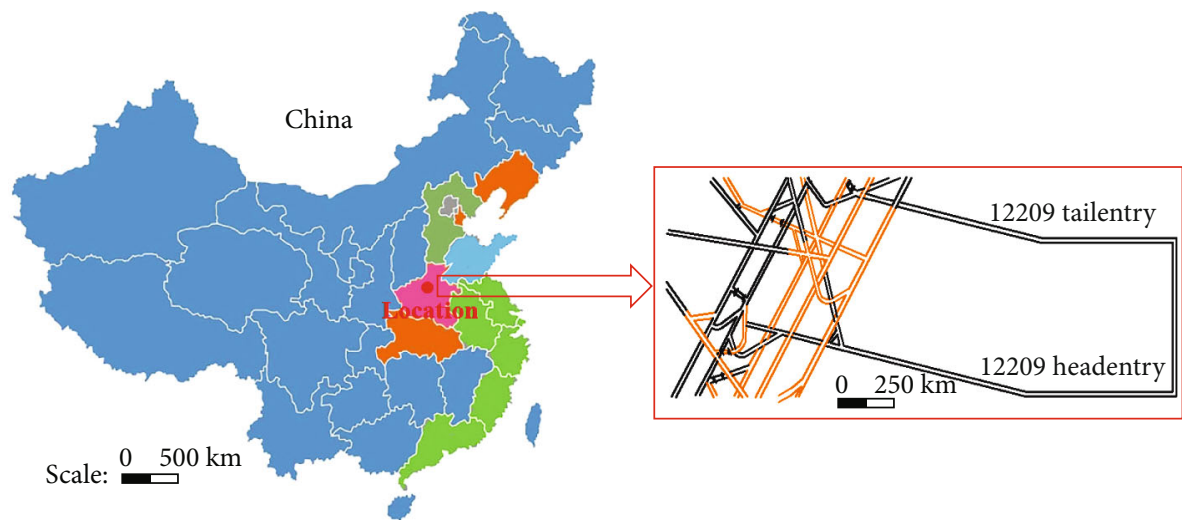

FIGURE 2: Location of the Zhaojiazhai mine and layout of the 12209 working face.

\begin{tabular}{|c|c|c|c|c|c|c|}
\hline Column & Lithology & $\begin{array}{c}\begin{array}{c}\text { Thickness } \\
(\mathrm{m})\end{array} \\
\end{array}$ & $\begin{array}{c}\mathrm{UCS} \\
(\mathrm{MPa}) \\
\end{array}$ & $\begin{array}{l}\text { Tensile strength } \\
(\mathrm{MPa})\end{array}$ & $\begin{array}{c}\text { Friction angle } \\
\left({ }^{\circ}\right)\end{array}$ & $\begin{array}{c}\text { Cohesion } \\
(\mathrm{MPa})\end{array}$ \\
\hline & $\begin{array}{l}\text { Fine sand } \\
\text { stone }\end{array}$ & 4.86 & --- & --- & --- & --- \\
\hline & Slit stone & 4.09 & --- & --- & --- & --- \\
\hline & $2{ }_{3}$ coal & 1.25 & --- & --- & --- & --- \\
\hline & $\begin{array}{c}\text { Sandy mud } \\
\text { stone }\end{array}$ & 0.87 & --- & --- & --- & --- \\
\hline & $\begin{array}{l}\text { Fine sand } \\
\text { stone }\end{array}$ & 20.0 & 96.83 & 8.78 & 47.5 & 22.9 \\
\hline 4 & $\begin{array}{c}\text { Sandy mud } \\
\text { stone }\end{array}$ & 2.30 & 20.19 & 1.55 & 17.5 & 9.1 \\
\hline & $2_{1}$ coal & 6.50 & 2.50 & 0.30 & 13.5 & 0.5 \\
\hline & $\begin{array}{l}\text { Sandy mud } \\
\text { stone }\end{array}$ & 8.86 & 27.55 & 1.91 & 21.3 & 10.6 \\
\hline
\end{tabular}

FIGURE 3: Physical and mechanical properties of the rock surrounding 12209 headentry. "UCS" stands for unconfined compressive strength.

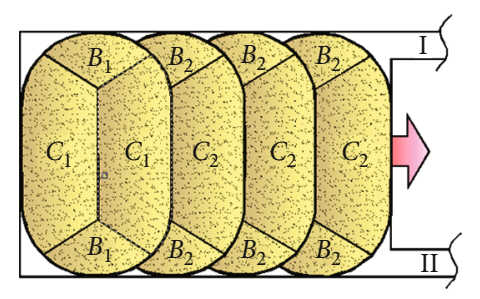

(a)

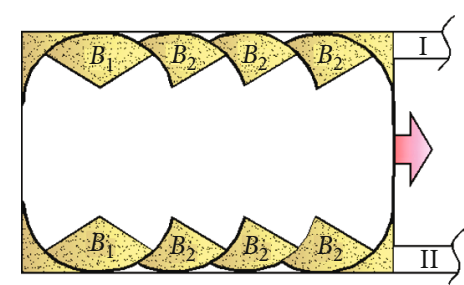

(b)

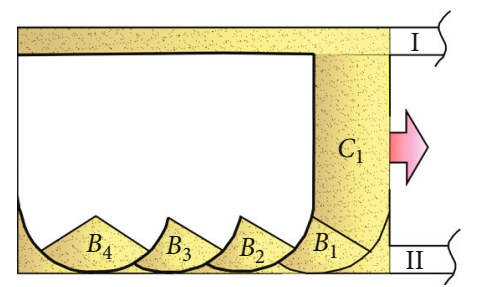

(c)

FIGURE 4: Main roof fractures and residual roof boundaries: (a) "O"-shaped cracks in the main roof. (b) Arc-shaped triangular blocks (ATBs) are formed after main roof collapse. (c) The overlying rock structure after roof cutting. 
(1) As mentioned previously, the $2{ }_{1}$ coal seam's main roof is a thick, hard, fine-grained sandstone. According to plate and shell mechanical analysis and field observations, as the longwall face advances, the main roof will continuously form crack lines parallel to the working face and then form "O"-shaped cracks along the sides of the panel. These cracks are shown in Figure 4(a). After block $\mathrm{C}$ behind the working face collapses, residual blocks of main roof strata remain as arc-shaped triangular block (ATB) B above the roadway, as shown in Figure 4(b) $[15,16]$. Under the geological conditions in the Zhaojiazhai mine, the length of the ATBs is larger than a traditional GER working face. In the early, transition, and later activity stage, the ATBs will produce more intense mining pressure [17-19]. The larger size of ATBs may break above the headentry or in the upper part of the coal rib, which seriously affects the quality of the retained entry [20]

To relieve stress on the strata and maintain the integrity of the roadway roof, presplitting blasting is used to cut off the main roof along a predetermined line [21]. As the working face advances, the ATBs break along this cutting seam and collapse so that the long cantilevered portion of the ATB is shortened, as shown in Figure 4(c).

Only two-thirds thickness of the main roof was cut off by the presplitting blasting so as to avoid increasing subsidence of the headentry roof that caused by the activity of main roof. The presplitting blasting depth also ensures that the ATBs could collapse completely along the cutting seam after periodical weighting.

(2) The coal seam is relatively thick, so it is necessary to construct a road-inside backfill body (RBB) to serve as a seal between the roadway and the gangue in the goaf [22]. The RBB should be designed to meet the following requirements:

(a) Roof control: the RBB should have enough early strength to support the roof and to prevent the roof over the gob-side entry from rotating and sinking.

(b) Mine safety: to ensure mine safety, the RBB should be wide enough and impermeable enough both to prevent mine air from leaking into the goaf and to prevent toxic gas in the goaf from leaking into the mine.

(3) The net width at the top of the existing 12209 headentry is $5.9 \mathrm{~m}$, and the roadway's width will be reduced after the RBB is constructed. To meet mine production requirements, it will be necessary to increase the width of the headentry on the coal rib side. Engineering analysis/numerical simulation software should be used to analyze the optimal expansion width

(4) The strength of $2_{1}$ coal seam is low, and the roof of the 12209 headentry is the top coal. After excavation and mining, plastic deformation occurs in the rock in the shallower parts of the roadway and stress transfer to the deeper parts of surrounding rock $[13,23]$. To reduce the deformation and damage to a wide roadway driven in soft coal seam, making and implementing a reasonable support and reinforcement plan are mandatory [24-28]. In this case, the large section coal roadway should be strengthened by grouting and then supported by bolt-mesh-anchors combined with constant resistance and large deformation (CRLD) anchor cables [29-31]

Because the technical scheme includes roadway expansion, roof cutting, and road-inside filling, the project's full name was Integrated Expanding-cutting-filling with Gobside Entry Retaining (IEGER). A cross section of the IEGER scheme in a thick three-soft seam is shown in Figure 5.

2.2. IEGER Design Implementation. To implement the design aforementioned, the IEGER was carried out using the four steps, sequentially: in Figure 6(a), 12209 headentry expansion ahead of the working face; in Figure 6(b), large section roadway with coal roof support; in Figure 6(c), blasting to cut the main roof; and in Figure 6(d), RBB construction behind the working face.

\section{Headentry Expansion Design}

3.1. Determination of Entry Width. The net width at the top of the 12209 headentry is $5.9 \mathrm{~m}$, and most RBBs are more than $1.5 \mathrm{~m}$ wide. To have the entry meet mine production requirements, the existing entry should be expanded by more than $2.0 \mathrm{~m}$. FLAC3D finite difference software was used to simulate failure of the surrounding rock for roadway expansions of $2.5,3.0,3.5$, and $4.0 \mathrm{~m}$. In the numerical simulation, the original entry was excavated first and the deformation was adjusted to zero. Then, the effect of headentry expansion on the surrounding rock was modeled. The numerical model is shown in Figure 7 . The model size (length $\times$ width $\times$ height ) was $80 \mathrm{~m} \times 4 \mathrm{~m} \times 62 \mathrm{~m}$ with 51,840 zones and 59,787 grid points. The horizontal and vertical model boundary displacements were limited. The load from the overlying strata was 6.6 MPa on the model's upper boundary, gravity was introduced, and the lateral pressure coefficient was 1.2. The Mohr Coulomb criterion was used to simulate the mechanical behavior of the rock [32].

As can be seen from Figure 8, roof subsidence increases with the entry expansion width. When the entry is expanded by either $2.5 \mathrm{~m}$ or $3.0 \mathrm{~m}$, the amounts the roadway roofs sink are nearly the same. When the expansion width reaches 3.5 $\mathrm{m}$, the roof-floor convergence increases considerably and the area of plastic deformation above the roof increases. At the $4.0 \mathrm{~m}$ entry expansion width, the immediate roof suffers plastic damage and roadway stability is clearly reduced. However, there is no significant difference in floor heave or rib deformation between the four entry expansion schemes and the plastic zone in the two ribs and the roadway floor are also not significantly different. The final width chosen for the 12209 headentry expansion was $3.5 \mathrm{~m}$. 


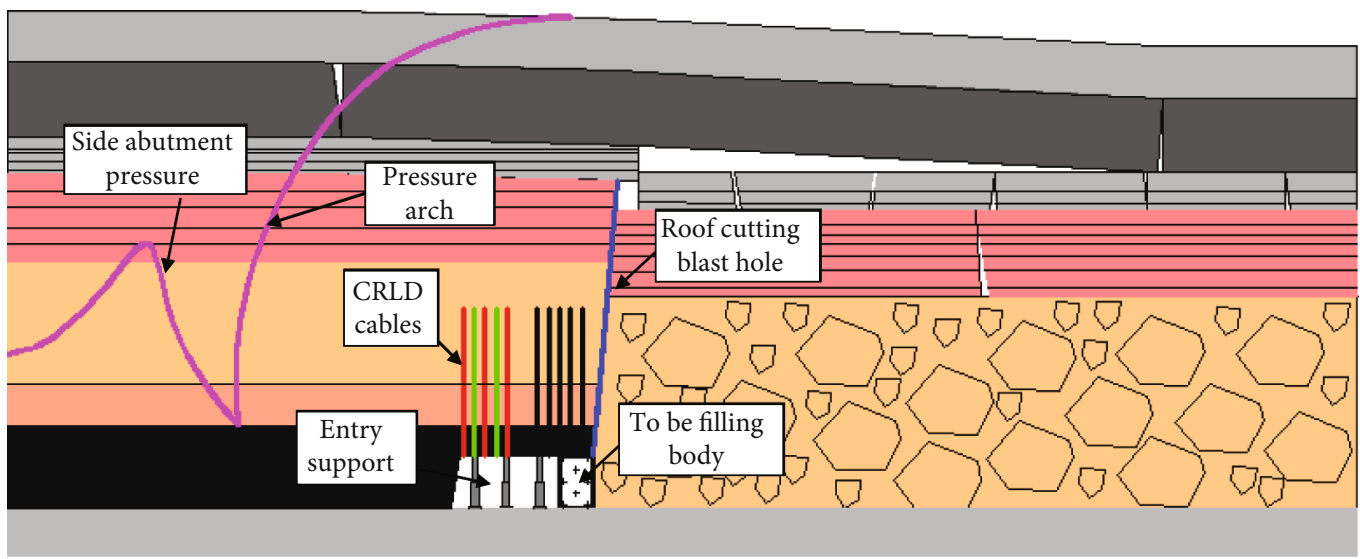

FIGURE 5: Illustrative cross section of Integrated Expanding-cutting-filling with Gob-side Entry Retaining (IEGER) scheme implemented in thick three-soft coal seam (TTCS).

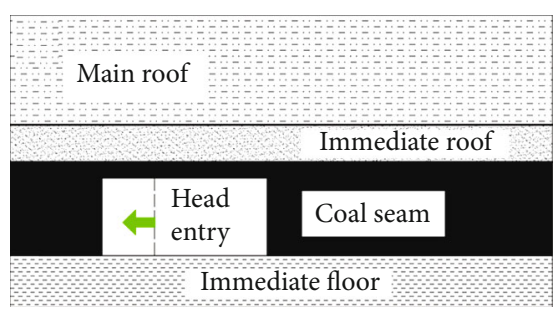

(a)

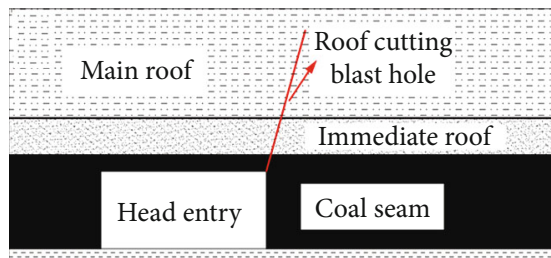

Immediate floor

(c)

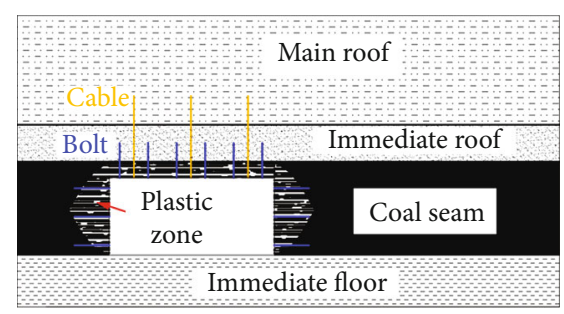

(b)

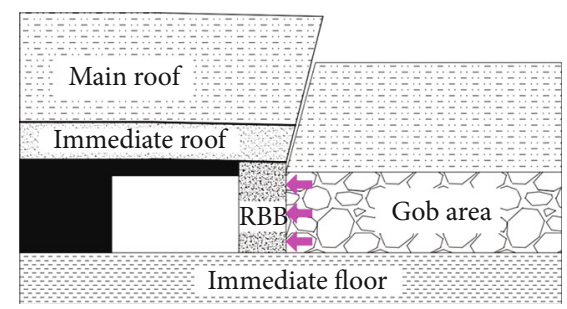

(d)

FIGURE 6: Main operations used to construct the IEGER.

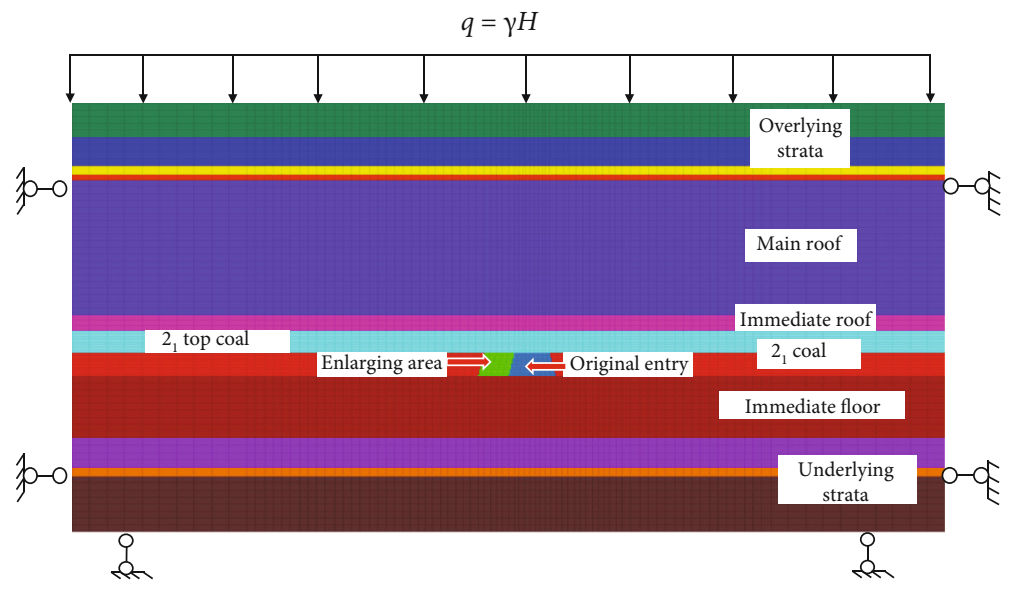

Figure 7: Headentry expansion numerical model. 


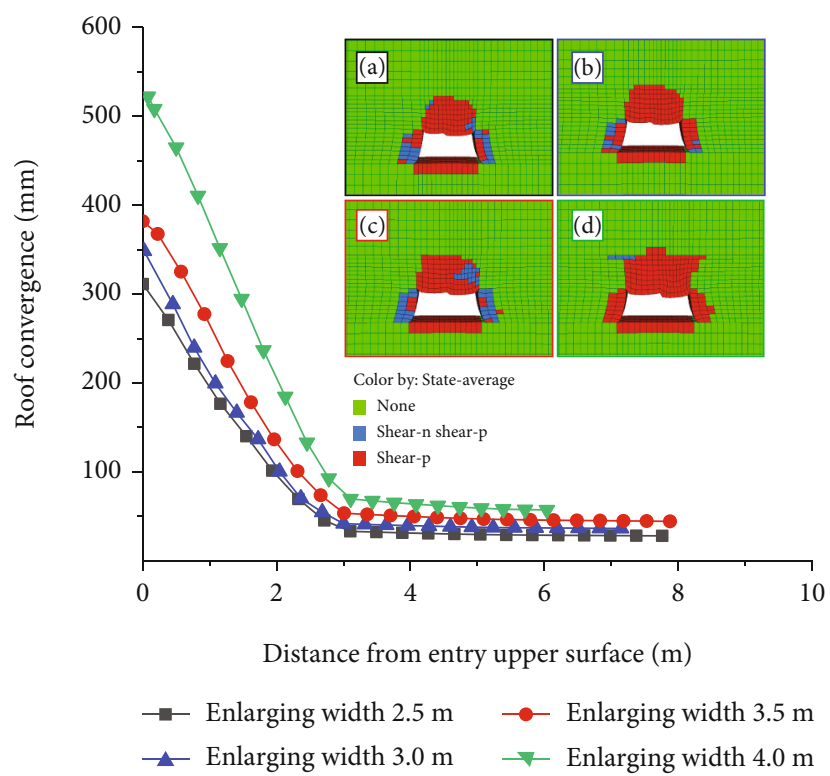

FIGURE 8: Graph showing roof subsidence and color-coded diagrams showing plastic zone distributions for different headentry expansion widths: (a) $2.5 \mathrm{~m}$, (b) $3.0 \mathrm{~m}$, (c) $3.5 \mathrm{~m}$, and (d) $4.0 \mathrm{~m}$.

3.2. Ground Support Methods. The net area of the new entry expansion is $10.71 \mathrm{~m}^{2}$ with an upper net width of $3.5 \mathrm{~m}$, a lower net width of $2.8 \mathrm{~m}$, and a net height of $3.4 \mathrm{~m}$. After entry expansion, the total area of the expanded roadway is $26.7 \mathrm{~m}^{2}$. As shown in Figure 9, the new roadway is $7.5 \mathrm{~m}$ wide at the roof and $8.7 \mathrm{~m}$ wide at the floor. Because the enlarged roadway will eventually serve as the tailentry for the 12207 working face, controlling deformation around the roadway is important for IEGER success.

In order to improve the strength of weak surrounding rock, grouting reinforcement measures are adopted to improve the overall strength of roadway surrounding rock [33]. And then, steel mesh, $\mathrm{H}$-shaped steel belts, bolts, cables, and CRLD cables were used as a combination of support.

High-strength bolts, $20 \mathrm{~mm}$ in diameter and $2400 \mathrm{~mm}$ long, were used to support the roof. The distances between two rows of bolt were $600 \mathrm{~mm}$ in the roof and $800 \mathrm{~mm}$ in the coal rib with bolts at $600 \mathrm{~mm}$ intervals in each row. The CRLD cables were $21.8 \mathrm{~mm}$ in diameter, and common $17.8 \mathrm{~mm}$ diameter cables were also used in the enlarged section of the roadway in a " $3-2-3$ " pattern along the roadway direction (" 2 " represents the use of an ordinary anchor cable, and " 3 " represents the use of a CRLD cable). The $\mathrm{W}$-shaped steel belts were installed along the roadway above the CRLD cables.

In the area influenced by front abutment pressure, three $1200 \mathrm{~mm}$ long $\pi$-shaped hinged top beams were used in combination with single hydraulic props to form "one beam and four columns" in the roadway $50 \mathrm{~m}$ ahead of the working face. Two $1200 \mathrm{~mm}$ long hinged top beams in the enlarged area were supported by two single hydraulic props. The distance between the single hydraulic prop is $1700 \mathrm{~mm}$, with row distances of $1600 \mathrm{~mm}$ (Figure 10).

\section{Roof Cutting Design and Blasting Parameters}

\subsection{Blasting Parameters}

(1) Binding energy tubes: the presplitting blasting used D-shaped binding energy tubes (DBETs). These tubes are made of antistatic and flame-retardant PVC; each DBET is $3 \mathrm{~m}$ long with a $24 \times 32 \mathrm{~mm}$ cross section (Figure 11(a)). The DBETs have two parts, a tube body and a cap that snaps on to the body. This makes charging the tubes simple (Figure 11(b)).

After blasting, only the rock in the plane of the binding energy groove will be broken; rock in the other directions will not be damaged. When used, the DBET is inserted into the blasthole with the binding energy groove aligned with the cutting line. The detonation wave generated by the explosion passes through the binding energy groove and converts the explosive's chemical energy into a high-pressure energy wave. The pressure can reach $7000 \mathrm{MPa}$, a pressure far greater than the dynamic compressive strength of the rock (about $200 \mathrm{MPa}$ ); cracks are generated in the blasthole wall. As shown in Figure 11(c), the detonation wave continues to travel along the cracks and generates concentrated tensile stress until the cracks from adjacent blastholes merge to form a penetrating crack [34], as shown in Figure 11(d).

(2) Charge structure and hole sealing: third classpermitted water gel explosive was the charge for the DBETs. After charging, five sections of DBET were installed in each roof cutting borehole (RCB). To reduce the loss of explosion energy and improve the effect of presplitting blasting, the borehole's sealed length should be $25 \%-30 \%$ of the total RCB length 


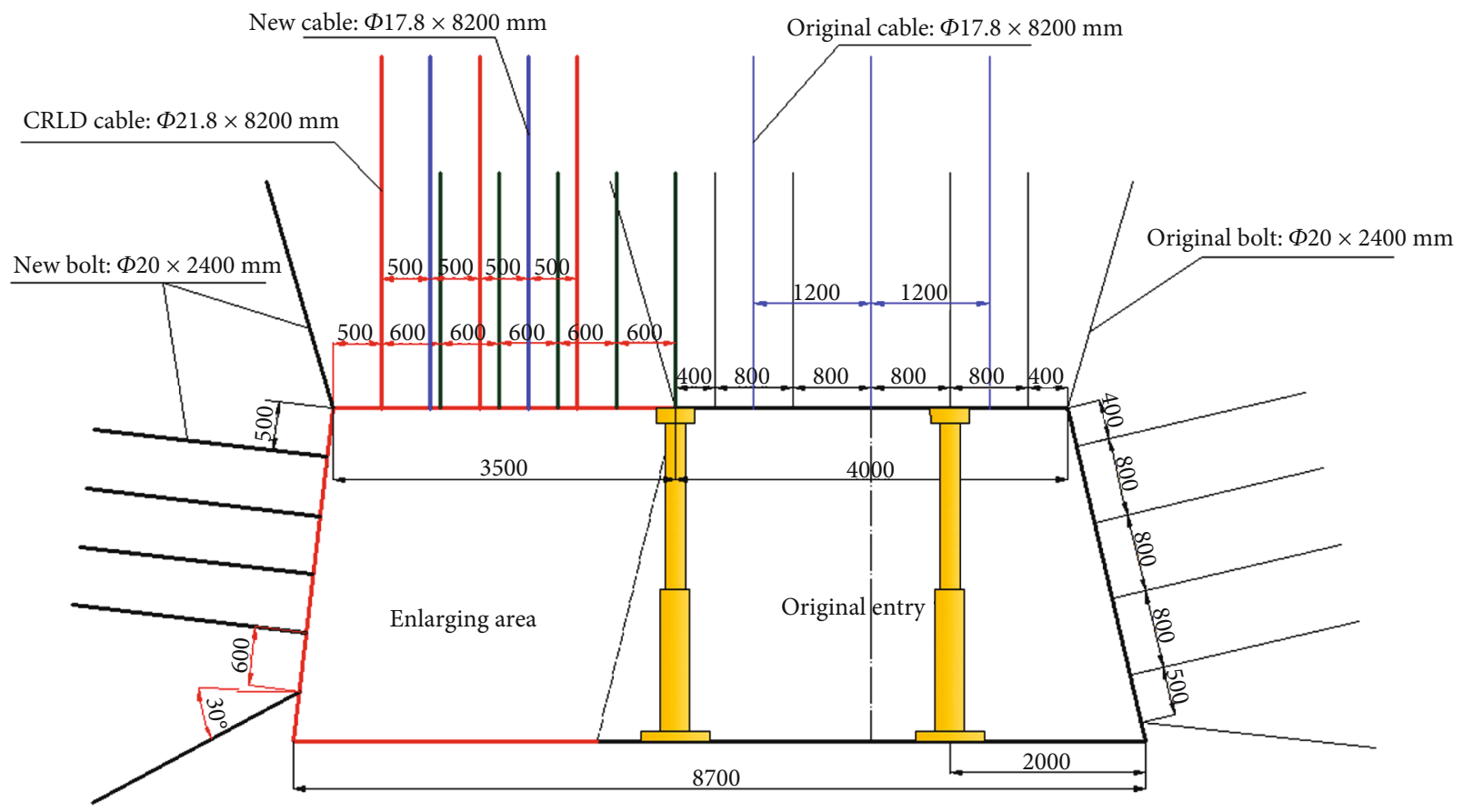

(a)

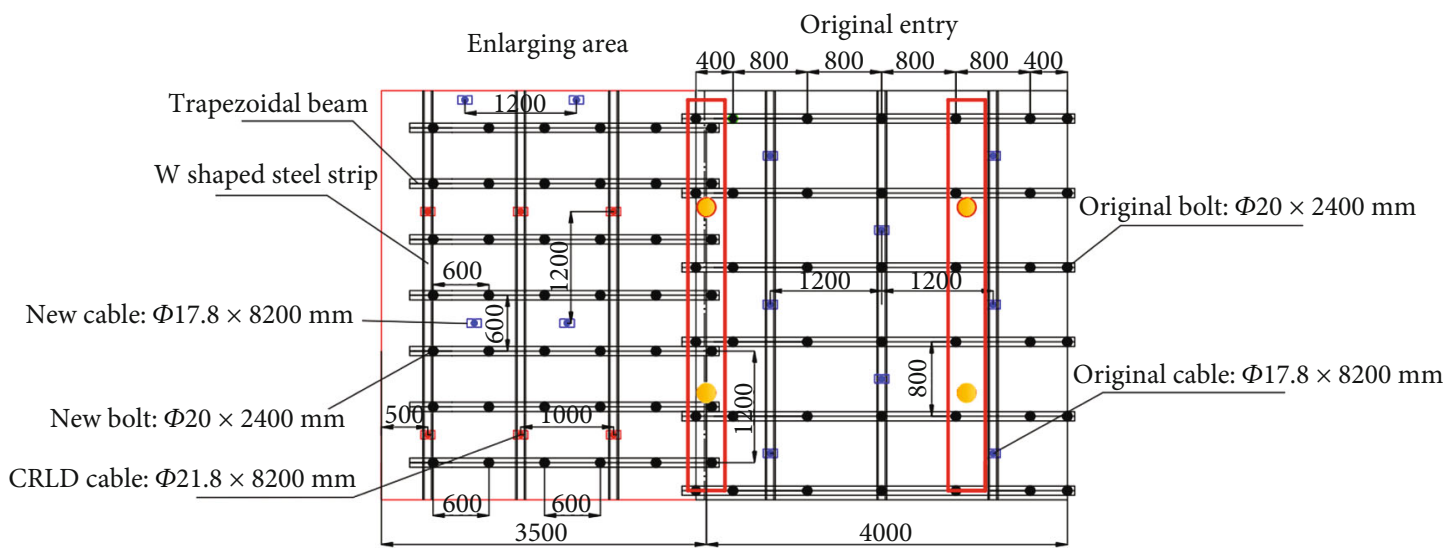

(b)

FIGURE 9: Diagrams showing supports used in the expanded roadway: (a) cross section; (b) map view of the roof (from below).

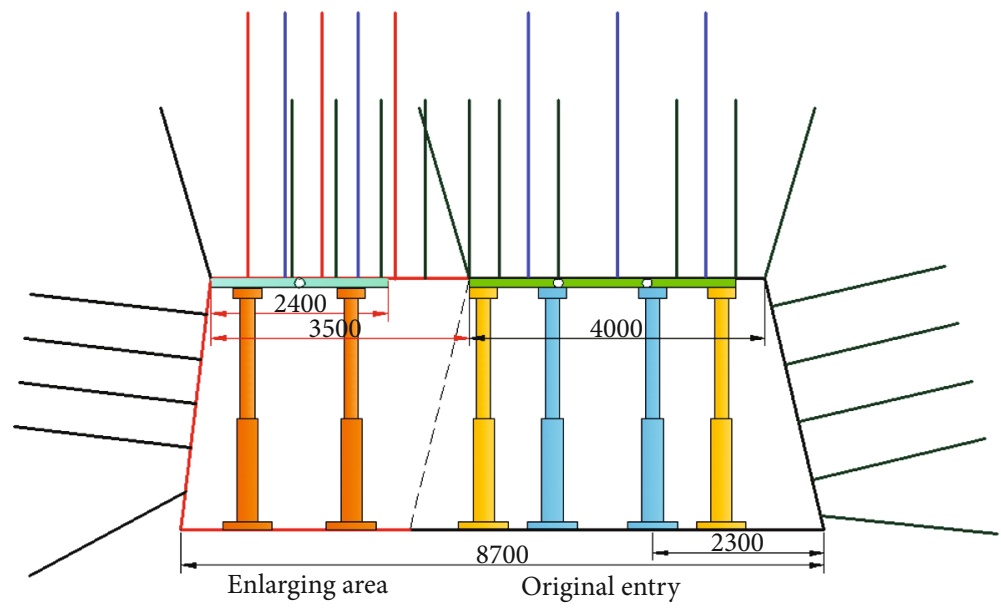

FIgURE 10: Supports in the area influenced by front abutment pressure. 


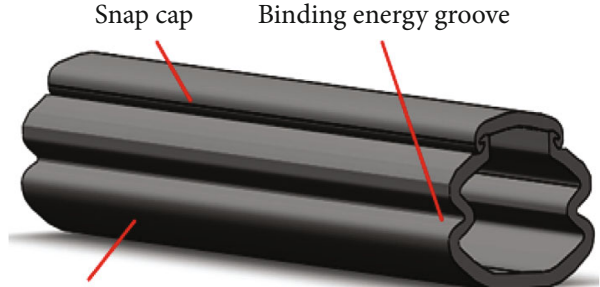

Tube body

(a)

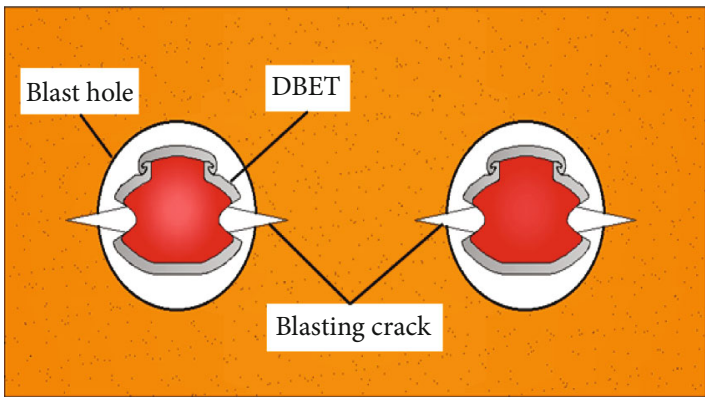

(c)

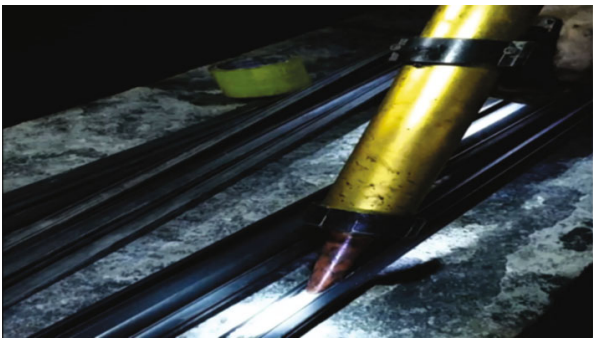

(b)

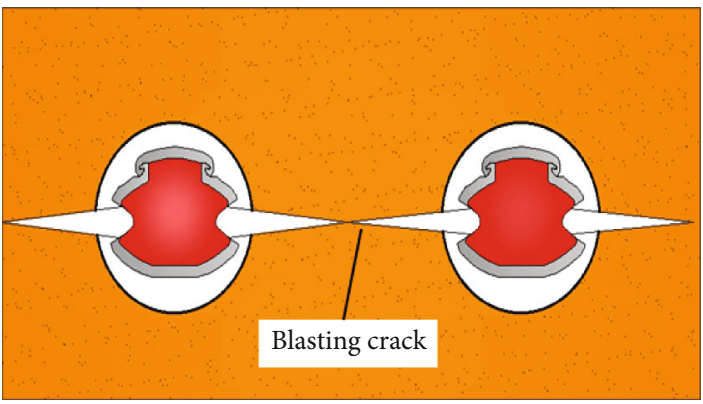

(d)

FIGURE 11: Illustrations showing a D-shaped binding energy tube (DBET), DBET charging, and blasting crack formation: (a) A DBET; (b) DBET being filled with water gel explosive; (c) Initial stage of crack generation; (d) crack penetration during the blast.

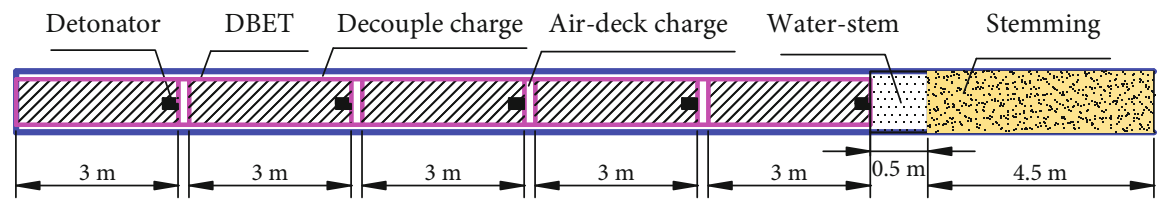

FIGURE 12: Schematic diagram of the charges and sealed lengths.

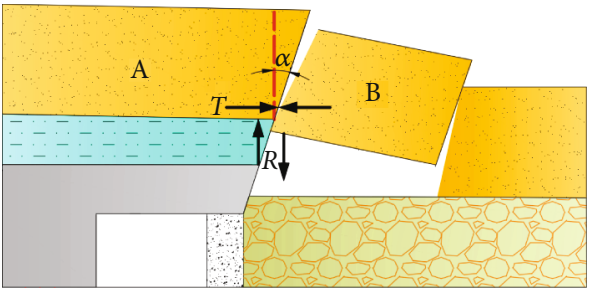

Figure 13: Mechanical mass balance model for the main roof after cutting.

[35], so for these RCBs, the sealing length was 5000 $\mathrm{mm}$. The charge locations in the hole and the sealed lengths are shown in Figure 12.

\subsection{Layout of Roof-Cutting Borehole (RCB)}

(1) RCB blasting distance of advance working face: to further improve the cutting effect, the blasting distance of advanced working face should be in the range of advanced abutment pressure and does not affect the coal mining operation of working face, so the distance determined as $30 \mathrm{~m}$.

(2) RCB length: according to 12209 working face drill data, to ensure that the main roof collapses completely and limits subsidence of the roof above the retained entry, about two-thirds thickness of the main roof should be cut off. So the RCBs should be $20 \mathrm{~m}$ long.

(3) RCB angle: the angle of an RCB refers to the angle between the drilled direction and the vertical. The blast forms a plane of fracture in the roof along the plane defined by the RCBs. As the working face advances, the main roof should be cut along this plane and collapse by the action of self-weight, overburden pressure, so the hinged structure should not be formed to increase the load of RBB.

An analysis of block $B$ in the mechanical model (the block on the goaf side of the RBB), as shown in Figure 13, shows that if block $B$ collapses along the fracture surface formed along the cutting line, it should meet the conditions represented by Equation (1) [36]:

$$
R \cos \theta-T \sin \theta>(R \sin \theta+T \cos \theta) \tan \varphi,
$$

where $T$ is the horizontal extrusion pressure between blocks $\mathrm{A}$ and $\mathrm{B}, R$ is the vertical extrusion pressure between the blocks, $\theta$ is the RCB angle, and $\varphi$ is the angle of internal 


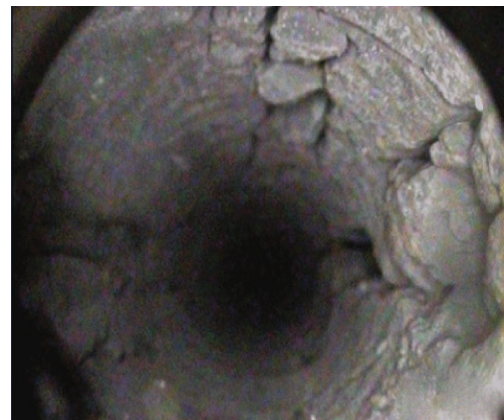

(a)

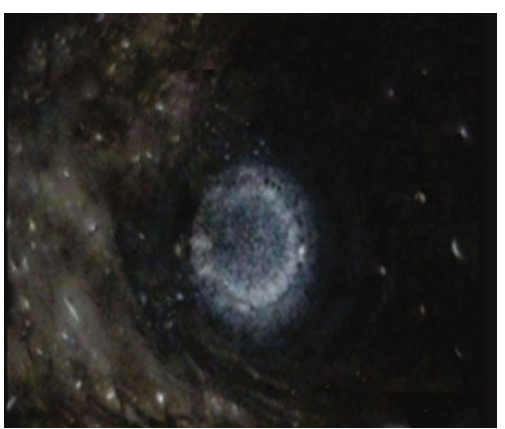

(b)

FIGURE 14: Inspection of cutting effect: (a) blasting crack in sides of borehole; (b) water outflow from adjacent borehole.

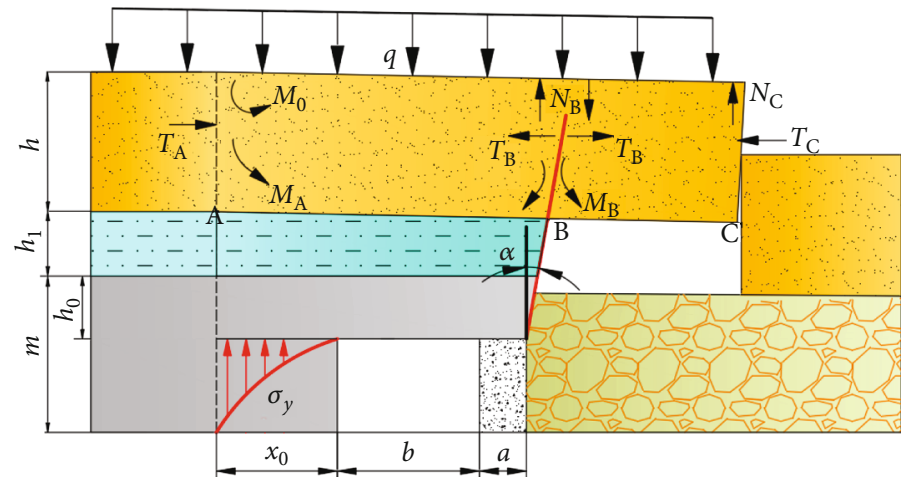

FIgURE 15: Bearing mechanic model for the RBB.

TABLE 1: Basic parameters needed for RBB support resistance calculation.

\begin{tabular}{lccc}
\hline $\begin{array}{l}\text { Basic } \\
\text { parameter }\end{array}$ & Value (unit) & $\begin{array}{c}\text { Basic } \\
\text { parameter }\end{array}$ & Value (unit) \\
\hline$m$ & $6.5(\mathrm{~m})$ & $q_{1}$ & 0.0575 \\
$\Delta S_{\mathrm{BC}}$ & $0.25(\mathrm{MN})$ & $R_{t}$ & $4.31(\mathrm{MPa})$ \\
$q$ & $3.3(\mathrm{MN} / \mathrm{m})$ & $h_{\mathrm{B}}^{\prime}$ & $6.5(\mathrm{~m})$ \\
$H$ & $300(\mathrm{~m})$ & $\alpha$ & $10\left(^{\circ}\right)$ \\
$T_{\mathrm{A}}$ & $6.8(\mathrm{MN})$ & $x_{0}$ & $2.2(\mathrm{~m})$ \\
$N_{\mathrm{A}}$ & $29.7(\mathrm{MN})$ & $K_{p}$ & 1.3 \\
$L_{\mathrm{BC}}$ & $23(\mathrm{~m})$ & $\varphi_{0}$ & $36.86\left(^{\circ}\right)$ \\
$M_{0}$ & $0(\mathrm{MN} \cdot \mathrm{m})$ & $C_{0}$ & $0.5(\mathrm{MPa})$ \\
$M_{\mathrm{A}}$ & $7(\mathrm{MN} \cdot \mathrm{m})$ & $\lambda$ & 0.35 \\
$M_{\mathrm{B}}$ & $35.41(\mathrm{MN} \cdot \mathrm{m})$ & $K_{c}$ & 1.5 \\
$\Delta S_{\mathrm{C}}$ & $5.35(\mathrm{~m})$ & $\sigma_{y}$ & $0.2(\mathrm{MPa})$ \\
$q_{0}$ & 0.0403 & & \\
\hline
\end{tabular}

friction for the main roof strata (taken to be $47.5^{\circ}$ ). Rearranged, Equation (1) becomes

$$
\theta<\arctan \frac{R}{T}-\varphi
$$

Calculations show that if $\theta<20.9^{\circ}$, block B can collapse to the goaf side and the fractured main roof block will not form a hinge. However, when the RCBs for the cutting line are drilled, the RCB angle should not be too small. If the angle is negative, the pressure between the roof blocks may increase roadway roof subsidence, and in addition, drilling and blasting may negatively affect the bolts and cables. If the angle is a little too low, explosive charging and hole sealing will be difficult. The RCB angle should also not be too large. If it is, the ATBs will be longer and this will not be conducive to headentry stability. In the end, the RCB drilling angle chosen was $10^{\circ}$.

(4) RCB spacing: according to the attenuation law of explosion stress wave, the damage radius for the explosion's stress waves can be calculated from Equation (2) [37]:

$$
R_{s}=r_{b}\left[\frac{\lambda P_{b}}{\left(1-D_{0}\right) \sigma_{t}+p}\right]^{1 / \alpha},
$$

where $\lambda$ is the coefficient of lateral pressure, $\lambda=\mu(1-\mu) ; \mu$ is the dynamic Poisson's ratio for the roof rock; $D 0$ is the initial damage coefficient of the rock (taken to be 0.6 ); $\sigma_{t}$ is the tensile strength of the roof rock $(\mathrm{MPa}) ; p$ is the initial stress $(\mathrm{MPa})$; and $s$ is the attenuation coefficient of stress waves during an explosion, $\alpha=2-\lambda$. 


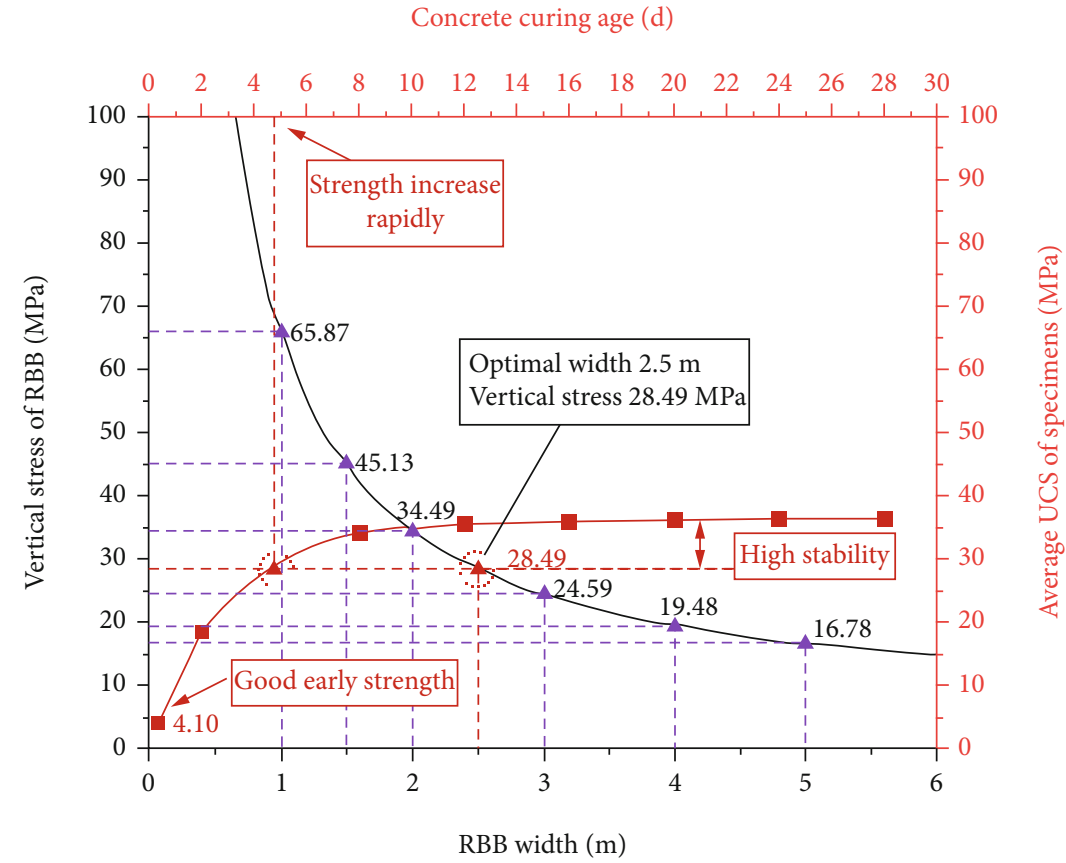

FIGURE 16: Fitting curve of bearing capacity and width of RBB and strength characteristic curve of filling material: (a) the black is fitting curve of vertical stress and width of RBB; (b) the red is strength characteristic curve of filling material.

TABLE 2: Road-inside backfill body (RBB) concrete filling material mix proportions.

\begin{tabular}{lcccccc}
\hline Item & \multicolumn{2}{c}{ Cementing material } & Water & \multicolumn{2}{c}{ Aggregate } & Additive \\
\hline Ingredient & Cement & Fly ash & Water & Gravel & Sand & ESA \& NSWA \\
Weight $\left(\mathrm{kg} / \mathrm{m}^{3}\right)$ & 400 & 80 & 185 & 950 & 700 & 5 \\
\hline
\end{tabular}

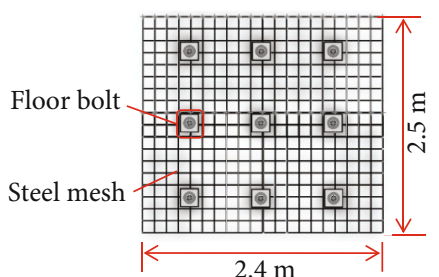

(a)

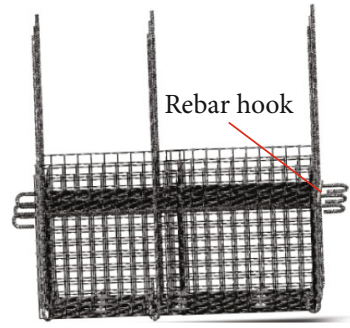

(c)

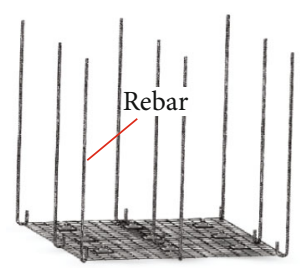

(b)

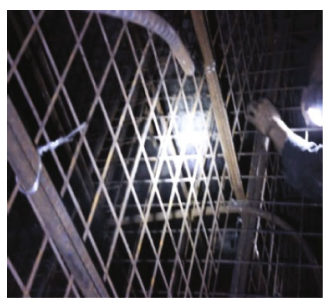

(d)

FIGURE 17: Diagrams showing selected steel mesh/rebar reinforcing cage construction steps (a-c) and a photograph of a portion of a finished cage (d). 


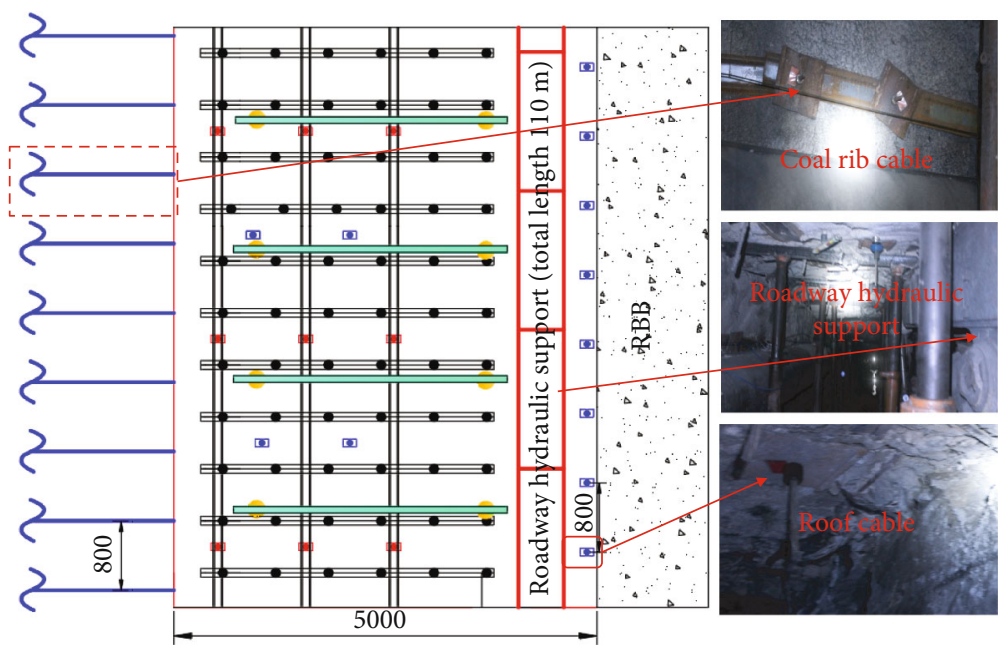

FIGURE 18: Plan-view diagram and photographs taken in the 12209 roadway illustrating the supplement support method used in the IEGER.

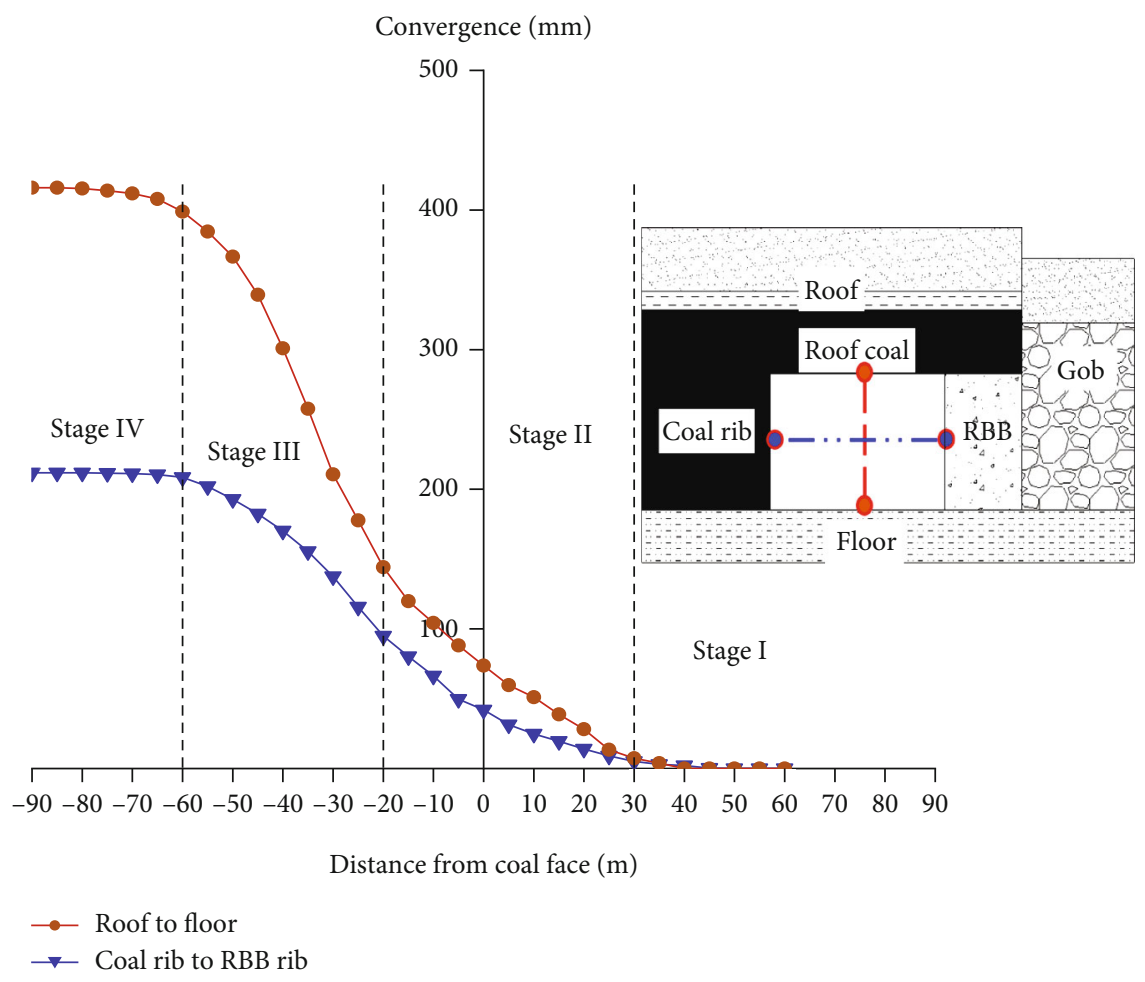

FIGURE 19: Deformation monitoring results of 12209 headentry.

After RCB blasting, the cracks produced by the explosions in adjacent blastholes should connect. Therefore, the distance $L$ between adjacent RBCs should be less than twice the blasting stress damage radius. That is,

$$
L \leq 2 r_{b}\left[1+\left\{\frac{\lambda P_{b}}{\left(1-D_{0}\right) \sigma_{t}+p}\right\}^{1 / \alpha}\right] .
$$

The peak pressure $P_{b}$ of the shock wave around an RCB is [38]

$$
P_{b}=P_{j}\left(\frac{r_{e}}{r_{b}}\right)^{2 \gamma}\left(\frac{l_{e}}{l_{b}}\right)^{\gamma} n
$$

where $r_{b}$ is the radius of the RCB (m); $r_{e}$ is the radius of explosive roll $(\mathrm{m}) ; l_{e}$ is the total length of the explosive rolls $(\mathrm{m}) ; l_{b}$ is the total length of charge section in the RCB (m); 
$\gamma$ is a constant related to the explosive's properties and charge density, generally $2-3$; and $n$ is the increasing coefficient of detonation product action (taken to be 11 for this water gel explosive).

The instantaneous detonation pressure $P_{j}$ of the explosive is

$$
P_{j}=\frac{\rho_{0} D_{j}^{2}}{2(\gamma+1)},
$$

where $\rho_{0}$ is the explosive density $\left(\mathrm{kg} / \mathrm{m}^{3}\right)$ and $D_{J}$ is the explosive detonation speed, generally taken to be $2000 \sim 4000 \mathrm{~m} / \mathrm{s}$.

According to the calculations, $P_{j}=3090 \mathrm{MPa}$ and $P_{b}=$ $2125 \mathrm{MPa}$. Substituting those values into Equation (4) indicates $L \leq 856 \mathrm{~mm}$. To ensure the cracks connect and make drilling easier, the spacing between adjacent RCBs was set to $700 \mathrm{~mm}$.

After blasting, some measures are taken to test the effect of roof cutting, including peep and inject water into borehole; results of borehole peeping indicate cracks formed on both sides of the borehole, as shown in Figure 14(a); the results of borehole water injection show water outflow from adjacent boreholes, as can be seen in Figure 14(b).

\section{Road-Inside Backfill Body (RBB) Design and Construction}

5.1. RBB Mechanical Analysis. As the working face advances, the immediate roof in the goaf collapses along the RBB under its own weight after it has been weakened by presplitting blasting. However, because the main roof is thick and hard, it is still intact and hangs over the goaf after the immediate roof has collapsed. Under the support of RBB, the overextended section $\mathrm{BC}$ of the main roof outside the $\mathrm{RBB}$ reaches the ultimate bending moment. When this occurs, the RBB is bearing its maximum load. A mechanical model for this situation is shown in Figure 15 [39].

For block BC, the static and moment balance conditions were expressed by

$$
\left\{\begin{array}{l}
T_{\mathrm{C}}=T_{\mathrm{B}}, \\
N_{\mathrm{B}}=N_{\mathrm{C}}+q L_{\mathrm{BC}}, \\
M_{\mathrm{B}}+T_{\mathrm{C}}\left(h-\Delta S_{\mathrm{C}}+\Delta S_{\mathrm{BC}}\right)-N_{\mathrm{C}} L_{\mathrm{BC}}-q L_{\mathrm{BC}}^{2} / 2=0,
\end{array}\right.
$$

where $T_{\mathrm{B}}$ is the horizontal extrusion pressure between block $\mathrm{AB}$ and block BC $(\mathrm{MN}), N_{\mathrm{B}}$ is the shear force in block BC at point $\mathrm{B}(\mathrm{MN}), N_{C}$ is the shear force in block $\mathrm{BC}$ at point $\mathrm{C}$
(MN), $M_{\mathrm{B}}$ is the bending moment of block $\mathrm{BC}$ at point $\mathrm{B}$ $(\mathrm{MN} \cdot \mathrm{m}), \Delta S_{\mathrm{BC}}$ is the settlement of block $\mathrm{BC}$ at point $\mathrm{C}$ (simplified as the deflection calculated for a cantilevered beam) (m), and $h$ is the thickness of main roof $(\mathrm{m})$.

$\Delta S_{\mathrm{C}}$ is the subsidence of the adjacent collapsed block on the right side of block $\mathrm{BC}(\mathrm{m})$ [36].

$$
\Delta S_{C}=h_{m}-h_{1}\left(K_{p}-1\right),
$$

where $h_{m}$ is the mining height $(\mathrm{m}), h_{1}$ is the thickness of immediate roof $(\mathrm{m})$, and $K_{p}$ is the rock fragmentation coefficient.

$T_{\mathrm{C}}$ is the horizontal thrust on block BC from the collapsed block $(\mathrm{MN})$

$$
T_{\mathrm{C}}=\frac{q L_{\mathrm{BC}}^{2}}{2\left(h-\Delta S_{\mathrm{BC}}\right)} \text {. }
$$

$L_{\mathrm{BC}}$ is the total length of the block BC overhang $(\mathrm{m})$

$$
L_{\mathrm{BC}}=2 h_{\mathrm{B}}^{\prime} \sqrt{\frac{R_{t}}{3 q}},
$$

where $R_{t}$ is the tensile strength of basic roof strata (MPa) and $h_{\mathrm{B}}^{\prime}$ is the uncut residual thickness of main roof $(\mathrm{m}) \cdot q$ is the weight of per unit length main roof and its upper soft rock layer $(\mathrm{Mn} / \mathrm{m})$.

$$
q=\frac{E_{i 1} h_{i 1}^{3}\left(\gamma_{i 1} h_{i 1}+\gamma_{i 2} h_{i 2}+\cdots+\gamma_{\text {in }} h_{\text {in }}\right)}{E_{i 1} h_{i 1}^{3}+E_{i 2} h_{i 2}^{3}+\cdots+E_{\text {in }} h_{\text {in }}^{3}},
$$

where $E_{i}$ is the elastic modulus of the $i$ th rock above the main roof $(\mathrm{MPa}), \gamma_{i}$ is the volume force of the $i$ th rock above the basic roof $\left(\mathrm{MN} / \mathrm{m}^{3}\right)$, and $h_{i}$ is the thickness of the $i$ th rock above the main roof $(\mathrm{m})$.

For block AB, a moment balance equation, Equation (12), has been established:

$$
\begin{aligned}
M_{0}+ & M_{A}+F\left(x_{0}+b+\frac{a}{2}\right)+\int_{0}^{x_{0}} \sigma_{y}\left(x_{0}-x\right) d x \\
& +T_{\mathrm{A}} h-M_{\mathrm{B}}-N_{\mathrm{B}}\left(x_{0}+b+a+h \tan \alpha\right) \\
& -\frac{q\left(x_{0}+b+a+h \tan \alpha\right)^{2}}{2}=0 .
\end{aligned}
$$

After calculating the loads from the immediate roof and the top coal, superposition was used to derive the equation to calculate RBB vertical stress:

$\sigma_{1}=K_{c} \frac{\left[M_{\mathrm{B}}+N_{\mathrm{B}}\left(x_{0}+b+a+h \tan \alpha\right)+\left(\left(q\left(x_{0}+b+a+h \tan \alpha\right)^{2}\right) / 2\right)+\left(\left(q_{1}\left(x_{0}+b+a\right)^{2}\right) / 2\right)+\left(\left(q_{0}\left(x_{0}+b+a\right)^{2}\right) / 2\right)-M_{0}-M_{\mathrm{A}}-\int_{0}^{x_{0}} \sigma_{y}\left(x_{0}-x\right) d x-T_{A} h\right]}{\left(x_{0}+b+(a / 2)\right) a}$, 
where $M_{\mathrm{A}}$ is the bending moment for block $\mathrm{AB}$ at point $\mathrm{A}$ $(\mathrm{MPa}), T_{\mathrm{A}}$ is the horizontal extrusion pressure for block $\mathrm{AB}$ at point $\mathrm{A}(\mathrm{MN}), M_{0}$ is the residual bending moment of $\mathrm{AB}$ at point $\mathrm{A}(\mathrm{MN} \cdot \mathrm{m}), q_{0}$ is the weight per unit length of the top coal $(\mathrm{Mn} / \mathrm{m}), q_{1}$ is the weight per unit length of the immediate roof $(\mathrm{Mn} / \mathrm{m}), b$ is the width of roadway $(\mathrm{m}), a$ is the width of the RBB (m), $\alpha$ is the roof cutting angle $\left({ }^{\circ}\right), K_{\mathrm{C}}$ is a safety factor, $x_{0}$ is the range of the limit equilibrium zone [40] (m), and $\sigma_{y}$ is the support stress for the limit equilibrium zone [41] (MPa).

Combined with the production geological conditions, the parameters to calculate the $\mathrm{RBB}$ support resistance are obtained, and the data are summarized in Table 1.

5.2. RBB Determination and Reinforcement. Formwork is used to build RBB. The filling material is a mixture composed of cement, gravel, sand, fly ash, early strength agent (ESA), and naphthalene sulfonate water-reducing admixture (NSWA). The filling material needed to meet the performance requirements.

By substituting the relevant values into Equation (13) in combination with the conditions at the 12209 working face, a curve representing the relationship between $\mathrm{RBB}$ vertical stress and width can be fitted. That curve is the black curve in Figure 16.

As shown in Figure 16, when the RBB is narrow, it needs to bear higher vertical stress. If the width of the RBB is greater than $2.5 \mathrm{~m}$, the change range of $\mathrm{RBB}$ vertical stress becomes smaller, but an increase in the $\mathrm{RBB}$ width will reduce the width of the headentry. An analysis of the variables shows that the optimal width of RBB is $2.5 \mathrm{~m}$; thus, the strength of the material used to construct the RBB must be more than 28.49 MPa.

Through mix proportion calculation and many tests, the filling materials that met the requirements have been prepared, as shown in Table 2. The results of uniaxial compressive strength versus with age were determined by experiment, as the red curve in Figure 16, where it can be seen that after curing about 5 days, the strength of filling material can reach 28.49 $\mathrm{MPa}$. The final strength is more than $35 \mathrm{MPa}$. The prepared material has both good early strength and high stability.

Before filling the RBB, first, clean the bottom of the formwork box. Then, lay the steel mesh on the floor and install 20 $\mathrm{mm}$ diameter by $2400 \mathrm{~mm}$ long floor bolts into the hard rock layer of the floor to compact the steel mesh. The spacing between the floor bolt is $600 \times 600 \mathrm{~mm}$, as shown in Figure 17(a). The longitudinal reinforcement and metal mesh are bound together, extending to $200 \mathrm{~mm}$ from the roof as shown in Figure 17(b). Then, attach a layer of transverse reinforcement every $800 \mathrm{~mm}$ and lay steel mesh. The ends of the transverse reinforcement are bent to form hooks and wrapped with polypropylene woven bags (Figure 17(c)). The hooks are overlapped and tied when the next reinforcing cage is put in place. A field photograph of a reinforcing cage is shown in Figure 17(d).

5.3. IEGER Supplemental Support. Controlling deformation of roadway side can reduce subsidence of roof. The calcula-

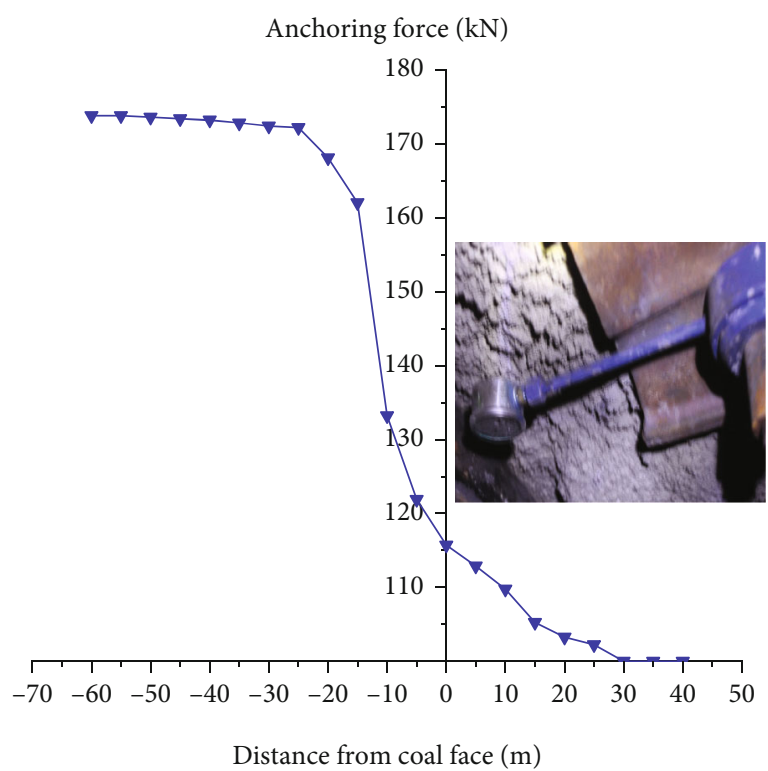

Figure 20: Monitoring results of anchor cable working resistance.

tions in Section 5.1 also show that the larger plastic area in the coal rib, the greater the bearing pressure on the RBB. Therefore, the supplemental control measures should be applied to coal rib. Steel cables, $17.8 \mathrm{~mm}$ in diameter and $6200 \mathrm{~mm}$ long with $800 \mathrm{~mm}$ apart, were attached $800 \mathrm{~mm}$ away from the roof at the coal rib. These were used in conjunction with $\mathrm{W}$-shaped steel belts to provide anchor cable prestress diffusion and reduce the amount of coal deformation.

During the initial $\mathrm{RBB}$ construction stages, roadway hydraulic supports were used to stabilize the roof and the RBB before the concrete was sufficiently solidified. Set along the $\mathrm{RBB}$, the roadway supports were emplaced from $50 \mathrm{~m}$ ahead to $60 \mathrm{~m}$ behind the working face. When the RBB behind the working face reached its final strength after curing for 28 days, the last supports behind the working face were withdrawn and moved to the ahead of the working face.

After the construction of a section of RBB was completed, a row of $17.8 \mathrm{~mm}$ diameter by $8200 \mathrm{~mm}$ long cables spaced $800 \mathrm{~mm}$ apart were installed at the roof $200 \mathrm{~mm}$ from the RBB [42]. These cables had a deviation angle of $12^{\circ}$ to the goaf side. The pretension force after anchoring should not be less than $25 \mathrm{MPa}$.

Figure 18 shows the supplement support schemes used in the IEGER.

\section{Field Monitoring and Analysis}

During the period of IEGER construction in the 12209 headentry, the mining pressures were observed and recorded. These observations included deformation of the rock surrounding the entry and the stress on the roof cables.

Figure 19 shows roof-to-floor and rib-to-rib convergences in the 12209 headentry after IEGER construction. Note that positive values on the abscissa are distances ahead the working face and the negative values denote distances 


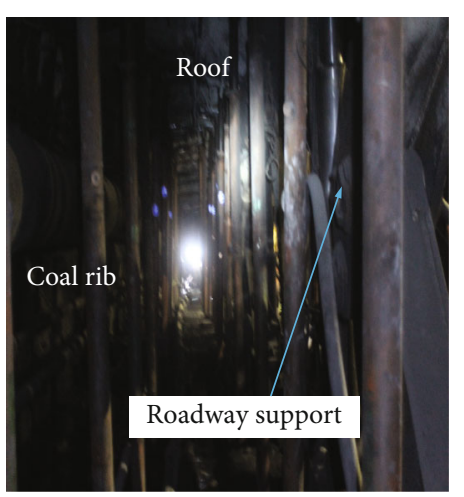

(a)

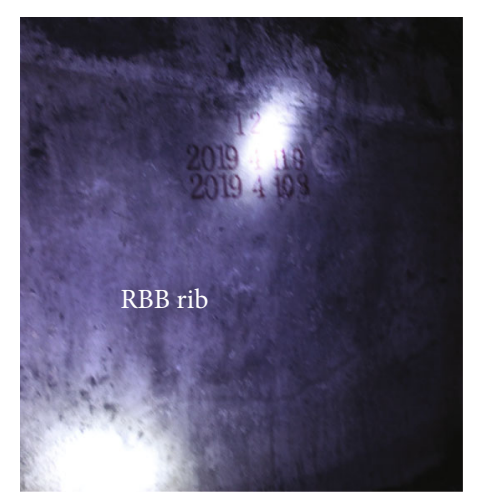

(b)

FIGURE 21: Surrounding rock control effect of the IEGER behind the working face: (a) cross section of the retained entry; (b) state of RBB.

behind the working face. It is clear when the two curves on Figure 19 are compared that roof-to-floor convergence is in all cases greater than the convergence between the two ribs; the difference between the two deformation rates is obvious. The surrounding rock deformation monitoring curves can be divided into four stages. In Stage I, $30 \mathrm{~m}$ or more ahead of the working face, the rock surrounding the entry has suffered no significant deformation. Stage II, +30 to $-20 \mathrm{~m}$, is the stage of mining influence, and in this stage, the deformation of the surrounding rock increases. The maximum roof-to-floor convergence at $-20 \mathrm{~m}$ is $144 \mathrm{~mm}$, and the maximum convergence between the two ribs at the same location is $95 \mathrm{~mm}$. Stage III, -20 to $-60 \mathrm{~m}$ behind the working face, is the influence stage of main roof movement and the deformation rate in this stage has increased considerably. Because the roof support scheme is effective and the coal rib has been reinforced in advance, the surrounding rock has little deformation. Stage IV is the deformation stability stage and in this stage the surrounding rock tend to be stable. The displacements of the entry roof and floor are basically stable at 416 $\mathrm{mm}$ (mainly from floor heave), and the final displacement of the two ribs is fairly constant at $212 \mathrm{~mm}$ (mainly from the coal rib).

Dynamometers were installed between the cable lock and the plate on some of the cables mounted in the middle of headentry to monitor the anchoring forces. The forces on cables ahead of and behind the working face are shown in Figure 20. Thirty meters ahead of the working face, the anchoring force on a cable is about $100 \mathrm{kN}$. As the working face advances, the forces on the anchoring cables increase significantly. At the measuring point $20 \mathrm{~m}$ behind the working face, the anchor cable stress has increased to $172 \mathrm{kN}$. After that, the working resistance on the cables no longer increases significantly as the working face advances and the forces on the cables tend to remain constant.

These steel cables, with nominal diameters of $17.8 \mathrm{~mm}$, are rated for a maximum load of $350 \mathrm{kN}$; the stress on a roof cable is less than 0.6 times breaking load of steel strand.

Photographs of the IEGER and the RBB behind the working face are shown in Figure 21. Constructed in TTCS, the IEGER effectively controls deformation in the surrounding rock and the roadway is now wide enough to meet the production requirements of the Zhaojiazhai coal mine.

\section{Conclusions}

(1) A new approach for GER integrated with expandingcutting-filling in TTCS is proposed and its principles explained. In the Zhaojiazhai coal mine, the construction scheme of IEGER was determined as follows: 12009 headentry advance expansion, large section entry support in TTS, advance blasting to cut roof, and construction of RBB

(2) FLAC3D numerical simulation software was used to determine the size of entry expansion. Steel mesh, $\mathrm{H}$-shaped steel belts, bolts, standard cables, and CRLD cables support the wide entry. Single props combined with hinged top beams are used within the influence range of front abutment pressure

(3) Binding energy blasting was used to cut off the thick and hard main roof along a predetermined line in advance of the working face to change the structure of the ATBs. This reduces the effect of the collapse and rotation of ATBs on the retaining entry and the $\mathrm{RBB}$

(4) Establishing the surrounding rock mechanical model, the width and strength of RBB were determined. The construction process of RBB and the reinforcement support scheme were formulated. The field observation results show that the technology in TTCS is feasible and effective

\section{Data Availability}

The data used to support the findings of this study are included within the article.

\section{Conflicts of Interest}

The authors declare no conflict of interest.

\section{References}

[1] "Statistical bulletin of national economic and social development of the People's Republic of China," 2020, http://www .stats.gov.cn/tjsj/zxfb/202102/t20210227_1814154.html/. 
[2] S. Zhao and A. Alexandroff, "Current and future struggles to eliminate coal," Resources Policy, vol. 129, pp. 511-520, 2019.

[3] X. H. Zhang, N. Winchester, and X. L. Zhang, "The future of coal in China," Energy Policy, vol. 110, pp. 644-652, 2017.

[4] G. R. Feng and P. F. Wang, "Stress environment of entry driven along gob-side through numerical simulation incorporating the angle of break," International Journal of Mining Science and Technology, vol. 30, no. 2, pp. 189-196, 2020.

[5] A. M. Suchowerska, R. S. Merifield, and J. P. Carter, "Vertical stress changes in multi-seam mining under supercritical longwall panels," International Journal of Rock Mechanics and Mining Sciences, vol. 61, pp. 306-320, 2013.

[6] S. L. Wang, S. P. Hao, Y. Chen, J. B. Bai, X. Y. Wang, and Y. Xu, "Numerical investigation of coal pillar failure under simultaneous static and dynamic loading," International Journal of Rock Mechanics and Mining Sciences, vol. 84, pp. 59-68, 2016.

[7] N. Zhang, C. L. Han, J. G. Kan, and X. G. Zheng, “Theory and practice of surrounding rock control for pillarless gob-side entry retaining," Journal of China Coal Society, vol. 39, no. 8, pp. 1635-1641, 2014.

[8] H. H. Sun and B. L. Zhao, Theory and Practice of Gob Side Entry Retaining, China Coal Industry Publishing House, Beijing, China, 1993.

[9] C. Wei, Application Research of Gob-side Retaining Entry in Flexible Formwork Paste-like Backfill Coalface [M.S. thesis], XI'AN University of Science and Technology, Xi'an, China, 2014.

[10] M. C. He, Y. B. Gao, J. Yang, and W. L. Gong, “An innovative approach for gob-side entry retaining in thick coal seam longwall mining," Energies, vol. 10, no. 11, p. 1785, 2017.

[11] X. G. Ma, M. C. He, J. Wang, Y. B. Gao, D. Y. Zhu, and Y. X. Liu, "Mine strata pressure characteristics and mechanisms in gob-side entry retention by roof cutting under medium-thick coal seam and compound roof conditions," Energies, vol. 11, no. 10 , p. 2539, 2018.

[12] X. Cheng, G. M. Zhao, Y. M. Li, X. R. Meng, and Q. Y. Tu, "Key technologies and engineering practices for soft-rock protective seam mining," International Journal of Mining Science and Technology, vol. 30, no. 6, pp. 148-158, 2020.

[13] M. F. Cai, M. C. He, and D. Y. Liu, Rock Mechanics and Engineering, Science Press, Beijing, China, 2013.

[14] M. Brook, B. Hebblewhite, and R. Mitra, "Coal mine roof rating (CMRR), rock mass rating (RMR) and strata control: Carborough Downs Mine, Bowen Basin, Australia," International Journal of Mining Science and Technology, vol. 30, no. 2, pp. 225-234, 2020.

[15] D. R. Zhu and M. G. Qian, "Structure and stability of main roof after its fracture," Journal of China University of Mining \& Technology, vol. 1, no. 1, pp. 21-30, 1990.

[16] C. J. Hou and X. H. Li, "Stability principle of big and small structures of rock surrounding roadwaydriven along goaf in fully mechanized top coal caving face," Journal of China Coal Society, vol. 26, no. 1, pp. 1-7, 2001.

[17] H. M. Li, "Control design of roof rocks for gob side entry," Chinese Journal of Rock Mechanics and Engineering, vol. 19, no. 5, pp. 651-654, 2000.

[18] N. Zhang, L. Yuan, C. L. Han, J. H. Xue, and J. G. Kan, "Stability and deformation of surrounding rock in pillarless gob-side entry retaining," Safety Science., vol. 50, no. 4, pp. 593-599, 2012.
[19] H. L. Zhang, M. Tu, H. Cheng, and Y. Z. Tang, "Breaking mechanism and control technology of sandstone straight roof in thin bedrock stope," International Journal of Mining Science and Technology, vol. 30, no. 2, pp. 259-263, 2020.

[20] H. P. Kang, D. L. Niu, Z. Zhang, J. Lin, Z. H. Li, and M. J. Fan, "Deformation characteristics of surrounding rock and supporting technology of gob-side entry retaining," Chinese Journal of Rock Mechanics and Engineering, vol. 29, no. 10, pp. 1977-1987, 2010.

[21] H. Liu, J. Dai, J. Q. Jiang, P. Wang, and J. Q. Yang, “Analysis of overburden structure and pressure-relief effect of hard roof blasting and cutting," Advances in Civil Engineering, vol. 2019, Article ID 1354652, 14 pages, 2019.

[22] H. Y. Yang, S. G. Cao, S. Q. Wang, Y. C. Fan, S. Wang, and X. Z. Chen, "Adaptation assessment of gob-side entry retaining based on geological factors," Engineering Geology, vol. 209, pp. 143-151, 2016.

[23] X. J. Hao, W. du, Y. X. Zhao et al., "Dynamic tensile behaviour and crack propagation of coal under coupled static- dynamic loading," International Journal of Mining Science and Technology, vol. 30, no. 5, pp. 659-668, 2020.

[24] Y. G. Zhang, Y. L. Xie, Y. Zhang, J. B. Qiu, and S. X. Wu, “The adoption of deep neural network (DNN) to the prediction of soil liquefaction based on shear wave velocity," Bulletin of Engineering Geology and the Environment, vol. 80, no. 6, article 2250, pp. 5053-5060, 2021.

[25] Y. G. Zhang, J. B. Qiu, Y. Zhang, and Y. Y. Wei, "The adoption of ELM to the prediction of soil liquefaction based on CPT," Natural Hazards, vol. 107, no. 1, article 4594, pp. 539-549, 2021.

[26] Y. Zhang, J. B. Qiu, Y. G. Zhang, and Y. L. Xie, "The adoption of a support vector machine optimized by GWO to the prediction of soil liquefaction," Environmental Earth Sciences, vol. 80, no. 9, p. 360, 2021.

[27] Y. G. Zhang, J. Tang, Z. Y. He, J. K. Tan, and C. Li, “A novel displacement prediction method using gated recurrent unit model with time series analysis in the Erdaohe landslide," Natural Hazards, vol. 105, no. 1, pp. 783-813, 2021.

[28] Y. G. Zhang and L. N. Yang, "A novel dynamic predictive method of water inrush from coal floor based on gated recurrent unit model," Natural Hazards, vol. 105, no. 2, article 4388, pp. 2027-2043, 2021.

[29] G. S. Wu, W. J. Yu, J. P. Zuo, and S. du, "Experimental and theoretical investigation on mechanisms performance of the rockcoal-bolt (RCB) composite system," International Journal of Mining Science and Technology, vol. 30, no. 6, pp. 759-768, 2020.

[30] H. W. Jing, J. Y. Wu, Q. Yin, and K. Wang, "Deformation and failure characteristics of anchorage structure of surrounding rock in deep roadway," International Journal of Mining Science and Technology, vol. 30, no. 5, pp. 593-604, 2020.

[31] J. H. Chen, F. L. He, and S. B. Zhang, "A study of the load transfer behavior of fully grouted rock bolts with analytical modelling," International Journal of Mining Science and Technology, vol. 30, no. 1, pp. 105-109, 2020.

[32] ITASCA, FLAC3D-Fast Lagrangian Analysis of Continua, Itasca Consulting Group Inc, Minneapolis, MN, 2012.

[33] C. Hildreth, F. Cybulski, C. Cook, and S. C. Tadolini, "When traditional ground support techniques aren't enough - chemical injections can solve complex problems," International Journal of Mining Science and Technology, vol. 30, no. 1, pp. 119-122, 2020. 
[34] "Xinglu energy conservation technology," //http://www .mediaunion.net/sxzx/18748.html.

[35] M. T. Gao and Y. Y. Wang, "Study and application on the technology of using the blasting to break roof to control rock burst," Journal of China Coal Society, vol. 36, no. S2, pp. 326-331, 2011.

[36] M. G. Qian, P. W. Shi, and J. L. Xu, Mine Pressure and Strata Control, China Mining University Press, Xuzhou, China, 2010.

[37] H. Jia and Y. Xu, "Study on stress damage zone in excavation of rock mass," Chinese Journal of Rock Mechanics and Engineering, vol. 26, no. S1, pp. 3489-3492, 2007.

[38] J. Dai, Rock Dynamic Characteristics and Blasting Theory, Metallurgical Industry Press, Beijing, China, 2013.

[39] J. B. Bai, H. Q. Zhou, X. Z. Tu, and D. Z. Yue, "Development of support technology beside roadway in goaf-side entry retaining for next sublevel," Journal of China University of Mining \& Technology, vol. 33, no. 2, pp. 59-62, 2004.

[40] H. H. Sun, J. Wu, and Y. X. Qiu, "Rules and ground pressure and strata control in gateways maintained in goaf," Journal of China Coal Society, vol. 17, no. 1, pp. 15-24, 1992.

[41] C. J. Hou and N. J. Ma, "Stress in in-seam roadway sides and limit equilibrium zone," Journal of China Coal Society, vol. 12, no. 4, pp. 21-29, 1989.

[42] M. Ghorbani, K. Shahriar, M. Sharifzadeh, and R. Masoudi, “A critical review on the developments of rock support systems in high stress ground conditions," International Journal of Mining Science and Technology, vol. 30, no. 5, pp. 555-572, 2020. 